Original Article

\title{
Obsessive-Compulsive Disorder in Singapore: Prevalence, Comorbidity, Quality of Life and Social Support
}

Mythily Subramaniam, ${ }^{1,2} M D, P h D$, Edimansyah $\underline{\text { Abdin }},{ }_{P h D}^{1}$, Janhavi Vaingankar, ${ }^{1} M S c$, Saleha $\underline{\text { Shafie, }},{ }_{B S o c S c i}$, Sherilyn hang, ${ }_{B S o c S c i}$, Esmond Seow, ${ }_{B A}$, Boon Yiang Chua, ${ }^{1}{ }_{M S c}$, Anitha Jeyagurunathan, ${ }^{1}$ MPhil (Social Work), Derrick Heng, ${ }^{3}$ MBBS, M hil (Epidemiology), FAMS, Kian Woon Kwok, ${ }^{4}{ }_{\text {PhD }}$, Siow Ann $\underline{\text { Chong, }{ }^{1} \text { MBBS, MMed (Psychiatry) }}$

\begin{abstract}
Introduction: Using data from Singapore Mental Health Study 2016 (SMHS 2016), we examined the prevalence of lifetime and 12-month obsessive-compulsive disorder (OCD), its sociodemographics correlates and association with comorbid psychiatric disorders and physical conditions, perceived social support and quality of life. Materials and Methods: The World Mental Health Composite International Diagnostic Interview (version 3.0) was administered by trained interviewers to 6126 residents aged $\geq 18$ years old to assess OCD prevalence and that of other select psychiatric disorders. Details on sociodemographics, perceived social support and health-related quality of life were obtained. Results: Lifetime and 12-month prevalence of $O C D$ was $3.6 \%$ and $2.9 \%$, respectively. Adjusted regression analysis showed that those with OCD had significantly higher odds of major depressive disorder (odds ratio [OR], 5.4), bipolar disorder (OR, 8.9), generalised anxiety disorder (OR, 7.3) and alcohol abuse (OR, 2.7). OCD was significantly associated with suicidal ideation and suicidality $(\mathrm{OR}, 5.1)$. OCD subjects also had higher odds of chronic pain $(O R, 2.4)$ and diabetes $(O R, 3.1)$. Finally, $O C D$ subjects had lower mean mental composite summary scores than controls (respondents without any of the psychiatric disorders and physical conditions included in SMHS 2016) and those with other lifetime psychiatric disorders and physical conditions. Conclusion: OCD prevalence in Singapore is high. Most people with OCD do not seek treatment despite experiencing significant comorbidity and loss of quality of life.
\end{abstract}

Ann Acad Med Singapore 2020;49:15-25

Key words: Composite International Diagnostic Interview, Epidemiology, Multi-ethnic, Psychiatric disorder, Survey

\section{Introduction}

Obsessive-compulsive disorder (OCD) is a severe psychiatric condition characterised by the presence of obsessions and/or compulsions. Obsessions are obtrusive and unwanted doubts, images, thoughts or urges that repeatedly intrude on the mind. Individuals who experience obsessions recognise them as unreasonable and excessive, and they arouse much anxiety and distress. To address their anxiety and distress, those suffering from OCD are driven to perform repetitive mental acts or behaviours, also known as compulsions. Common obsessions include thoughts about contamination, pathological doubt and order/symmetry; common compulsions include checking, counting, washing and ensuring precision and symmetry. ${ }^{1}$

OCD is a relatively common disorder with an estimated lifetime prevalence that ranges from $1.5-3.5 \%$ in both men and women..$^{2-4}$ Age of OCD onset displays a bimodal pattern, with symptoms appearing in childhood/adolescence more frequently in men and in early adulthood in women. ${ }^{5}$ Comorbidity with anxiety and mood disorders is commonly seen in OCD and is associated with worsening of symptoms and quality of life. ${ }^{6,7}$ Studies also suggest a significant

${ }^{1}$ Research Division, Institute of Mental Health, Singapore

${ }^{2}$ Lee Kong Chian School of Medicine, Nanyang Technological University, Singapore

${ }^{3}$ Epidemiology and Disease Control Division, Ministry of Health, Singapore

${ }^{4}$ School of Social Sciences, Nanyang Technological University, Singapore

Address for Correspondence: A/Prof Mythily Subramaniam, Research Division, Institute of Mental Health, Buangkok Green Medical Park, 10 Buangkok View, Singapore 539747.

Email: mythily@imh.com.sg 
association between OCD and suicidality. ${ }^{8}$ Data from the Swedish national patient register revealed that OCD patients had an increased risk of attempting suicide and dying by suicide than matched cohort controls even after adjusting for psychiatric comorbidities. ${ }^{9}$ However, OCD tends to remain largely unrecognised and untreated ${ }^{3,10,11}$ with significant treatment delays. ${ }^{12}$

The behavioural symptoms of OCD can significantly affect marital and social relationships of individuals who may also perceive poor social support from their partners, family and friends. Studies have shown that OCD patients often feel disconnected from their families ${ }^{13}$ in some instances, there may even be significant conflicts that contribute to divorce, marital discord and poor relationships. ${ }^{14}$ However, few studies have examined perceived support among those with OCD in the community.

Singapore is a multiracial country with a resident population of about 4 million comprising Chinese (74.3\%), Indians (9.0\%) and Malays (13.4\%). ${ }^{15}$ The first Singapore Mental Health Study in 2010 (SMHS 2010) was a nationally representative survey of the adult population aged $\geq 18$ years old, and its findings had established a high prevalence of lifetime and 12-month OCD in the population. ${ }^{16}$

The second Singapore Mental Health Study in 2016 (SMHS 2016) ${ }^{17}$ employed the same methodology as SMHS 2010 to establish prevalence of select psychiatric disorders in the population. Consequently, SMHS2016had established that the prevalence of lifetime and 12-month OCD in the population was $3.6 \%$ and $2.9 \%$, respectively. ${ }^{17}$ While the initial article from SMHS 2016 examined the association between OCD and sociodemographics, it did not examine the association between OCD and comorbid conditions and its impact on functional status and quality of life. ${ }^{17} \mathrm{As}$ such, this study aims to deepen current understanding of age of OCD onset, its severity and association with comorbid psychiatric disorders and physical conditions, perceived social support and quality of life in Singaporeans.

\section{Materials and Methods}

Data was collected as part of SMHS 2016 which was a nation-wide, epidemiological study of Singapore residents aged $\geq 18$ years old. Respondents were randomly selected from a national database that maintains the names and sociodemographics - such as age, ethnicity, gender and household addresses - of all residents in Singapore. The respondents were visited at the household address and their written consent to be interviewed was sought - including that of parents and guardians of respondents aged $\leq 21$ years old - before any study-related procedures were initiated. The study was described in greater detail in an earlier article. ${ }^{17}$
Residents excluded from the survey included those who could not be interviewed due to severe physical or psychiatric conditions, resided overseas, lived in institutions or hospitals throughout the period of the survey, were unable to converse in Chinese, English or Malay (languages in which questionnaires were available) and could not be contacted due to incomplete or incorrect household addresses.

A sociodemographic questionnaire was administered to all respondents. Data on age, ethnicity (Chinese, Malay, Indian and Others), gender, marital status (not married, married, divorced/separated or widowed), educational level (primary and below, secondary, vocational, preuniversity/junior college, diploma and university), employment (employed, unemployed and economically inactive, that is, students, homemakers and retirees) and household income were collected. Household income was derived from mean pre-tax income of all family members living in the same household in the past 12 months.

Psychiatric disorders were defined according to the criteria found in the Diagnostic and Statistical Manual of Mental Disorders, $4^{\text {th }}$ Edition (DSM-IV), ${ }^{18}$ and were established in respondents using the World Mental Health Composite International Diagnostic Interview version 3.0 (WMH-CIDI 3.0) developed by the World Health Organization. ${ }^{19}$ The diagnostic modules for 12-month and lifetime prevalence of the disorders identified in the survey were classified into 3 categories: 1) affective disorders that included major depressive disorder (MDD) and bipolar disorder; 2) anxiety disorders that encompassed generalised anxiety disorder (GAD) and OCD; and 3) alcohol use disorder that comprised alcohol abuse and alcohol dependence. Suicidal behaviours-suicide ideation, suicide plan and suicide attempt—were identified using the "Suicidality" component of WMH-CIDI 3.0.

The Yale-Brown Obsessive-Compulsive Scale (Y-BOCS $)^{20}$ which is incorporated into WMH-CIDI 3.0 was used to determine clinical severity of 12 -month cases. We employed the cutoffs for symptoms suggested by Storch et $\mathrm{al}^{21}$ that ranged from mild (0-13) to moderate (14-25), moderate-severe (26-34) and severe (35-40). The Sheehan Disability Scale (SDS) was used to assess functional impairment in respondents diagnosed with 12-month OCD and classified as mild, moderate and serious. ${ }^{22}$

The 12-Item Short Form Health Survey (SF-12) was used to examine 8 domains of physical and mental health in respondents. The results were aggregated into Mental Component Summary (MCS) and Physical Component Summary (PCS) scores. ${ }^{23}$ A high reading on both scores indicates better health.

The Multidimensional Scale of Perceived Social Support (MSPSS) was used to examine the extent of perceived 
social support in respondents. MSPSS was developed as a questionnaire to measure perceptions of support from one's family, friends and significant others. ${ }^{24}$ Studies in Singapore have shown that it has good internal reliability with a stable factorial structure. ${ }^{25,26}$ The scale ranges from 1-7 and a higher score indicates greater perceived social support.

Respondents also reported on whether they suffered from any of the 18 chronic medical conditions prevalent in Singapore including asthma, cardiovascular diseases (such as angina, congestive heart failure, coronary heart disease, heart attack, major paralysis and stroke), chronic pain (such as arthritis, back and spinal disc issues, headaches, migraine and rheumatism), diabetes, hyperlipidaemia and hypertension.

All estimates were weighted to adjust for over-sampling and non-response, and were post-stratified for age and ethnicity distributions between the survey sample and the Singapore resident population in 2014. Mean and standard error of the mean were calculated for continuous variables, and frequencies and percentages were derived for categorical variables. Descriptive analyses were performed to describe the sociodemographics of respondents and to establish lifetime and 12-month prevalence of obsession, compulsions, OCD and role impairment in 12-month OCD cases. Logistic regression analyses of the sociodemographic correlates of lifetime and 12-month OCD were used to generate odds ratio and $95 \%$ confidence intervals - to examine the associations between lifetime OCD and comorbid psychiatric disorders and physical conditions - after adjusting for age, gender and ethnicity.

Significant differences in OCD prevalence in SMHS 2010 and SMHS 2016 were examined with chi-square tests. Perceived social support and quality of life scores in those with lifetime OCD, other psychiatric disorders, physical conditions and controls were compared using multiple linear regression analysis after adjusting for age, gender and ethnicity. For this study, controls were defined as respondents without any of the physical conditions and psychiatric disorders that were included in SMHS 2016. Standard errors and significance tests were estimated using Taylor series linearisation method. All statistical analyses were performed with Statistical Analysis Systems (SAS) software version 9.3 (SAS Institute Inc., Cary, NC, USA).

This study was approved by the Domain-Specific Review Board of the National Healthcare Group of Singapore.

\section{Results}

A total of 6126 residents were interviewed and the response rate was $69.5 \%$. Men and women comprised $49.6 \%$ and $50.4 \%$, respectively, of all respondents. Most of them were aged $18-49$ years (60\%), gainfully employed $(72 \%)$ and married $(60 \%)$.

Lifetime prevalence of obsessions and compulsions is shown in Table 1. The prevalence of obsessions or compulsions $(\mathrm{O} / \mathrm{C})$ was $11.5 \%$. The most common $\mathrm{O} / \mathrm{C}$ symptom was ordering (4.7\%). Lifetime and 12-month prevalence of OCD was $3.6 \%$ and $2.9 \%$, respectively. Based on symptom severity, 12-month OCD was classified as mild (Y-BOCS $<14)$, moderate and moderate-severe in $127(75.1 \%), 41(24.3 \%)$ and $1(0.6 \%)$ case, respectively. Mean and median age of OCD onset were 19.4 years and 15 years, respectively.

Sociodemographic correlates of 12-month and lifetime OCD are shown in Table 2A. After controlling for sociodemographic factors in multiple logistic regression analyses, female gender was significantly associated with higher odds of 12-month OCD while those aged 50-64 years old and $\geq 65$ years old (as compared to those aged 18-34 years old) had lower odds of OCD. Among those with lifetime disorder, those aged 50-64 years old and $\geq 65$ years old had lower odds as compared to those aged 18-34 years old. Finally, Malay ethnicity was significantly associated with higher odds of lifetime disorder as compared to those of Chinese ethnicity (Table 2B).

Respondents with 12-month OCD reported a mean of 2.6 (median, 0 ) days in the past year when they were "totally unable to work or carry out their activities due to OCD". According to SDS criteria of functional impairment, most of those with OCD $(87.7 \%)$ had a mild form of the disorder and $12.2 \%$ had a moderate form.

In respondents with lifetime OCD, $92(53.2 \%)$ had other comorbid psychiatric disorders (Table 3). MDD was the most common comorbid disorder and was present in 51 $(28.2 \%)$ respondents. Findings from logistic regression analysis indicated that those with OCD had significantly higher odds of alcohol abuse, bipolar disorder, dysthymia, GAD and MDD. Additionally, OCD was significantly associated with suicidal ideation and suicidality.

A total of 121 (52.3\%) respondents with lifetime OCD had a comorbid physical disorder (Table 3 ). Chronic pain was the most prevalent condition and it was reported by 64 (33.2\%) respondents. Logistic regression analysis also revealed that those with OCD had higher odds of chronic pain and diabetes.

Respondents with OCD had significantly lower mean MSPSS scores in perceived social support from family, friends and significant others than those with physical disorders and controls (Table 4). They also had significantly lower mean scores in role physical, bodily pain, general health, vitality, social functioning, role emotional and mental health domains as well as lower MCS scores than 
Table 1. Lifetime Prevalence of Obsessions, Compulsions and OCD

\begin{tabular}{|c|c|c|c|c|c|c|}
\hline \multirow[t]{2}{*}{ Variable } & \multicolumn{3}{|c|}{ Survey Sample $(n=6126)$} & \multicolumn{3}{|c|}{ Respondents With Lifetime OCD $(n=217)$} \\
\hline & $\mathbf{n}$ & $\%$ & SE & $\mathbf{n}$ & $\%$ & SE \\
\hline \multicolumn{7}{|l|}{ Obsession } \\
\hline Contamination & 153 & 2.4 & 0.3 & 63 & 28.0 & 4.4 \\
\hline Harming & 117 & 2.0 & 0.3 & 49 & 23.7 & 4.2 \\
\hline Ordering & 252 & 4.0 & 0.4 & 87 & 44.6 & 4.9 \\
\hline Hoarding & 237 & 3.6 & 0.3 & 70 & 33.2 & 4.6 \\
\hline Others & 135 & 2.1 & 0.3 & 59 & 25.4 & 4.2 \\
\hline Any of the above & 544 & 8.8 & 0.5 & 182 & 81.6 & 3.9 \\
\hline \multicolumn{7}{|l|}{ Number of obsessions } \\
\hline 1 & 318 & 5.4 & 0.4 & 88 & 35.8 & 4.6 \\
\hline 2 & 137 & 1.9 & 0.2 & 55 & 23.3 & 4.1 \\
\hline 3 & 61 & 1.2 & 0.2 & 28 & 18.1 & 4.0 \\
\hline 4 & 21 & 0.2 & 0.1 & 9 & 3.9 & 1.9 \\
\hline 5 & 7 & 0.1 & 0.0 & 2 & 0.5 & 0.3 \\
\hline \multicolumn{7}{|l|}{ Compulsion } \\
\hline Washing/cleaning & 102 & 1.3 & 0.2 & 46 & 16.7 & 3.5 \\
\hline Checking & 209 & 3.3 & 0.3 & 82 & 39.8 & 4.8 \\
\hline Ordering & 170 & 2.6 & 0.3 & 74 & 36.1 & 4.7 \\
\hline Hoarding & 165 & 2.3 & 0.3 & 54 & 24.8 & 4.2 \\
\hline Others & 145 & 2.0 & 0.2 & 61 & 26.3 & 4.2 \\
\hline Any of the above & 479 & 7.2 & 0.5 & 174 & 81.8 & 3.7 \\
\hline \multicolumn{7}{|c|}{ Number of compulsions } \\
\hline 1 & 294 & 4.4 & 0.4 & 87 & 41.1 & 4.9 \\
\hline 2 & 97 & 1.5 & 0.2 & 47 & 23.7 & 4.3 \\
\hline 3 & 59 & 0.9 & 0.2 & 28 & 13.7 & 3.4 \\
\hline 4 & 19 & 0.2 & 0.1 & 8 & 2.6 & 1.3 \\
\hline 5 & 10 & 0.1 & 0.0 & 4 & 0.7 & 0.4 \\
\hline \multicolumn{7}{|c|}{ Obsessions/compulsions } \\
\hline Contamination & 193 & 2.8 & 0.3 & 79 & 33.1 & 4.6 \\
\hline Checking & 209 & 3.3 & 0.3 & 82 & 39.8 & 4.8 \\
\hline Ordering & 303 & 4.7 & 0.4 & 105 & 54.0 & 4.9 \\
\hline Hoarding & 312 & 4.5 & 0.4 & 88 & 39.2 & 4.8 \\
\hline Other obsessions & 135 & 2.1 & 0.3 & 59 & 25.4 & 4.2 \\
\hline Other compulsions & 145 & 2.0 & 0.2 & 61 & 26.3 & 4.2 \\
\hline Harming & 117 & 2.0 & 0.3 & 49 & 23.7 & 4.2 \\
\hline Any of the above & 727 & 11.5 & 0.6 & 217 & 100.0 & 0.0 \\
\hline \multicolumn{7}{|c|}{ Number of obsessions/compulsions } \\
\hline 1 & 387 & 6.5 & 0.5 & 76 & 34.7 & 4.7 \\
\hline 2 & 157 & 2.4 & 0.3 & 52 & 24.1 & 4.3 \\
\hline 3 & 86 & 1.3 & 0.2 & 38 & 18.6 & 3.8 \\
\hline 4 & 52 & 0.8 & 0.2 & 33 & 11.6 & 2.9 \\
\hline$>5$ & 45 & 0.6 & 0.1 & 18 & 11.0 & 3.2 \\
\hline
\end{tabular}

OCD: Obsessive-compulsive disorder; SE: Standard error 
Table 2A. Sociodemographic Correlates for 12-Month and Lifetime OCD

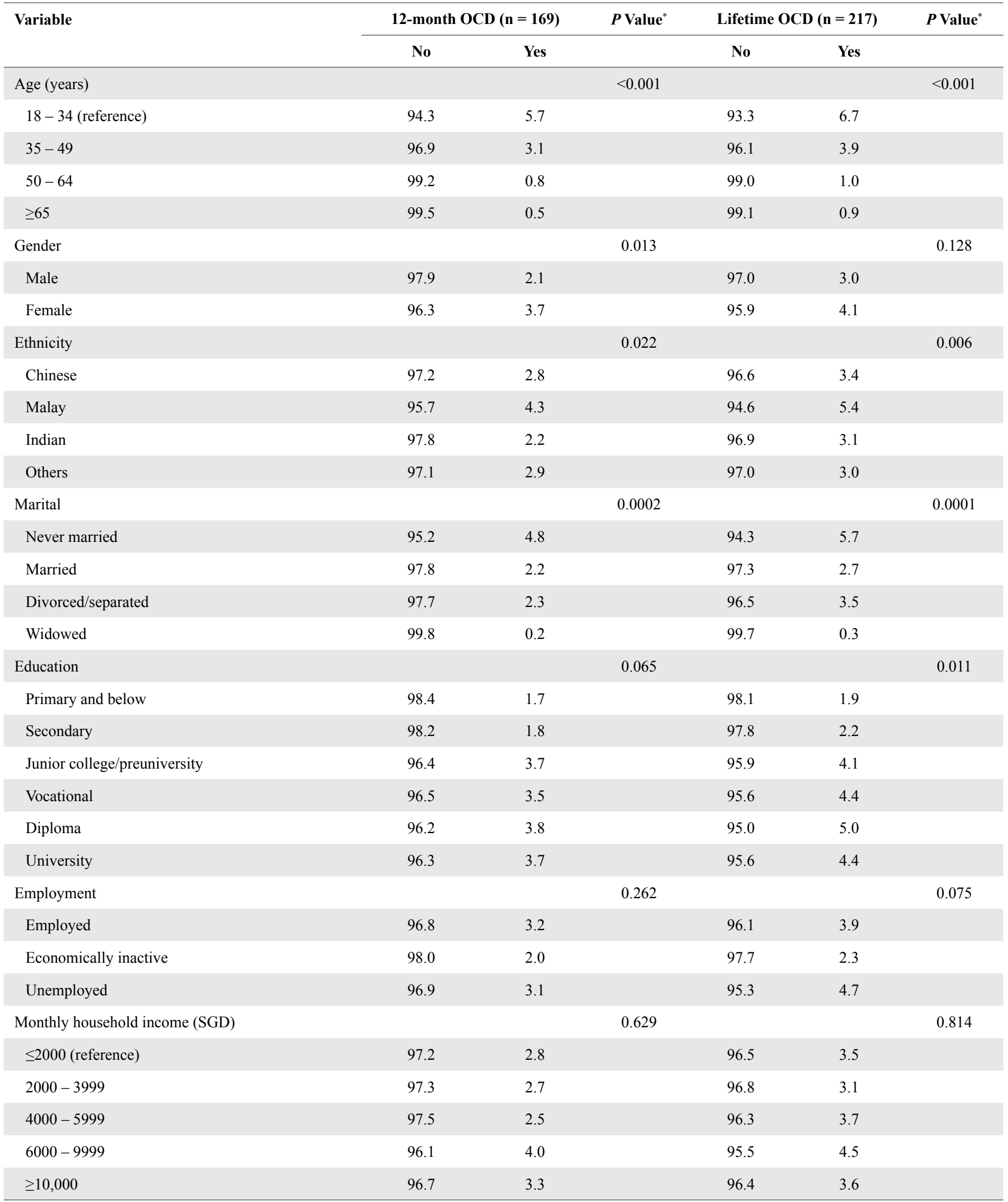

OCD: Obsessive-compulsive disorder; SGD: Singapore dollar

${ }^{*}$ Chi-square analyses. 
Table 2B. Sociodemographic Correlates for 12-Month and Lifetime OCD

\begin{tabular}{|c|c|c|c|c|c|c|}
\hline \multirow[t]{2}{*}{ Variable } & \multicolumn{3}{|c|}{ 12-Month OCD } & \multicolumn{3}{|c|}{ Lifetime OCD } \\
\hline & OR & $95 \%$ CI & $P$ Value $^{*}$ & OR & $95 \%$ CI & $P$ Value $^{*}$ \\
\hline \multicolumn{7}{|l|}{ Age (years) } \\
\hline \multicolumn{7}{|l|}{$18-34$ (reference) } \\
\hline $35-49$ & 0.5 & $0.3-1.03$ & 0.061 & 0.6 & $0.3-1.0$ & 0.064 \\
\hline$\geq 65$ & 0.1 & $0.03-0.3$ & 0.001 & 0.1 & $0.0-0.3$ & 0.000 \\
\hline \multicolumn{7}{|l|}{ Gender } \\
\hline \multicolumn{7}{|l|}{ Male (reference) } \\
\hline Female & 1.8 & $1.1-2.9$ & 0.016 & 1.5 & $1.0-2.2$ & 0.084 \\
\hline \multicolumn{7}{|l|}{ Chinese (reference) } \\
\hline Malay & 1.5 & $0.9-2.3$ & 0.103 & 1.6 & $1.0-2.4$ & 0.030 \\
\hline Indian & 0.8 & $0.5-1.2$ & 0.256 & 0.9 & $0.6-1.3$ & 0.466 \\
\hline Others & 0.96 & $0.5-1.9$ & 0.912 & 0.8 & $0.4-1.6$ & 0.553 \\
\hline \multicolumn{7}{|l|}{ Marital status } \\
\hline \multicolumn{7}{|l|}{ Married (reference) } \\
\hline Never married & 1.3 & $0.7-2.4$ & 0.376 & 1.2 & $0.7-2.1$ & 0.547 \\
\hline Divorced/separated & 1.1 & $0.3-3.8$ & 0.881 & 1.4 & $0.5-3.9$ & 0.577 \\
\hline Widowed & 0.3 & $0.1-1.9$ & 0.208 & 0.3 & $0.1-1.3$ & 0.108 \\
\hline \multicolumn{7}{|l|}{ Education } \\
\hline Primary and below & 1.7 & $0.6-4.6$ & 0.307 & 1.3 & $0.5-3.2$ & 0.539 \\
\hline Secondary & 1.04 & $0.5-2.2$ & 0.927 & 0.9 & $0.5-1.8$ & 0.801 \\
\hline Junior college/preuniversity & 1.5 & $0.6-4.1$ & 0.411 & 1.2 & $0.5-3.2$ & 0.680 \\
\hline Vocational & 1.05 & $0.4-2.6$ & 0.922 & 0.9 & $0.4-2.0$ & 0.804 \\
\hline Diploma & 1.1 & $0.5-2.1$ & 0.84 & 1.1 & $0.6-2.0$ & 0.854 \\
\hline \multicolumn{7}{|l|}{ Employment } \\
\hline \multicolumn{7}{|l|}{ Employed (reference) } \\
\hline Economically inactive & 0.7 & $0.4-1.3$ & 0.223 & 0.6 & $0.4-1.1$ & 0.128 \\
\hline Unemployed & 1.1 & $0.4-2.8$ & 0.834 & 1.4 & $0.7-2.9$ & 0.374 \\
\hline \multicolumn{7}{|c|}{ Monthly household income (SGD) } \\
\hline \multicolumn{7}{|l|}{$\leq 2000$ (reference) } \\
\hline $2000-3999$ & 0.5 & $0.2-1.1$ & 0.068 & 0.5 & $0.3-0.9$ & 0.027 \\
\hline $4000-5999$ & 0.4 & $0.2-0.96$ & 0.039 & 0.6 & $0.3-1.1$ & 0.091 \\
\hline $6000-9999$ & 0.7 & $0.3-1.6$ & 0.401 & 0.6 & $0.3-1.3$ & 0.236 \\
\hline$\geq 10,000$ & 0.7 & $0.3-1.7$ & 0.383 & 0.6 & $0.3-1.3$ & 0.201 \\
\hline
\end{tabular}

CI: Confidence interval; OCD: Obsessive-compulsive disorder; OR: Odds ratio; SGD: Singapore dollar

"Multiple logistic regression analyses. 
Table 3. Comorbidity of Lifetime OCD with Other Psychiatric Disorders and Physical Conditions $(\mathrm{n}=217)$

\begin{tabular}{|c|c|c|c|c|c|c|c|c|c|}
\hline \multirow[t]{2}{*}{ Disorder/Condition } & \multicolumn{3}{|c|}{ Yes } & \multicolumn{3}{|c|}{ No } & \multicolumn{3}{|c|}{ Multiple Logistic Regression* } \\
\hline & $\mathbf{n}$ & $\%$ & SE & $\mathbf{n}$ & $\%$ & SE & OR & $95 \% \mathrm{CI}$ & $P$ Value \\
\hline \multicolumn{10}{|l|}{ Psychiatric disorder } \\
\hline Major depressive disorder & 51 & 28.2 & 4.6 & 166 & 71.8 & 4.6 & 5.4 & $3.3-8.8$ & $<.0001$ \\
\hline Dysthymia & 6 & 3.2 & 1.8 & 211 & 96.8 & 1.8 & 11.8 & $3.2-42.7$ & 0.000 \\
\hline Generalised anxiety disorder & 17 & 9.9 & 3.2 & 200 & 90.1 & 3.2 & 7.3 & $3.2-16.5$ & $<.0001$ \\
\hline Alcohol abuse & 23 & 10.9 & 3.1 & 194 & 89.1 & 3.1 & 2.7 & $1.3-5.5$ & 0.005 \\
\hline Alcohol dependence & 5 & 0.9 & 0.4 & 212 & 99.1 & 0.4 & 1.4 & $0.5-3.9$ & 0.540 \\
\hline Any of the above psychiatric disorder & 92 & 53.2 & 4.9 & 125 & 46.8 & 4.9 & 7.9 & $5.2-12.0$ & $<.0001$ \\
\hline \multicolumn{10}{|l|}{ Suicidality } \\
\hline Ideation & 56 & 32.6 & 4.8 & 161 & 67.4 & 4.8 & 5.1 & $3.2-8.2$ & $<0.0001$ \\
\hline Plan & 10 & 3.1 & 1.5 & 207 & 96.9 & 1.5 & 1.5 & $0.5-4.4$ & 0.433 \\
\hline Attempt & 13 & 4.7 & 2.0 & 204 & 95.3 & 2.0 & 2.6 & $0.9-6.9$ & 0.055 \\
\hline Any suicidality & 56 & 32.6 & 4.8 & 161 & 67.4 & 4.8 & 5.1 & $3.2-8.2$ & $<0.001$ \\
\hline \multicolumn{10}{|l|}{ Physical condition } \\
\hline Hypertension & 35 & 13.2 & 3.2 & 182 & 86.8 & 3.2 & 1.3 & $0.7-2.6$ & 0.400 \\
\hline Hyperlipidaemia & 37 & 15.3 & 3.6 & 179 & 84.7 & 3.6 & 1.6 & $0.8-3.1$ & 0.158 \\
\hline Diabetes & 25 & 10.7 & 3.0 & 192 & 89.3 & 3.0 & 3.1 & $1.5-6.4$ & 0.003 \\
\hline Asthma & 34 & 10.6 & 2.7 & 183 & 89.4 & 2.7 & 0.6 & $0.4-1.1$ & 0.114 \\
\hline Cardiovascular disease & 9 & 3.6 & 1.9 & 208 & 96.4 & 1.9 & 1.8 & $0.5-5.7$ & 0.339 \\
\hline Ulcer & 7 & 1.2 & 0.5 & 210 & 98.8 & 0.5 & 0.8 & $0.3-1.8$ & 0.538 \\
\hline Thyroid disease & 3 & 0.3 & 0.2 & 214 & 99.7 & 0.2 & 0.1 & $0.0-0.5$ & 0.003 \\
\hline Cancer & 3 & 0.4 & 0.2 & 214 & 99.6 & 0.2 & 0.3 & $0.1-1.3$ & 0.110 \\
\hline Any of the above physical condition & 121 & 52.3 & 4.9 & 96 & 47.7 & 4.9 & 1.5 & $1.0-2.2$ & 0.067 \\
\hline
\end{tabular}

CI: Confidence interval; OCD: Obsessive-compulsive disorder; OR: Odds ratio; SE: Standard error

*Estimates were derived from logistic regression and adjusted for age, ethnicity and gender.

controls and those with any lifetime other psychiatric disorders and physical conditions.

\section{Discussion}

The findings of this study corroborated the results from the last nation-wide study that established the prevalence of OCD. ${ }^{3}$ OCD remains a prevalent condition with significant treatment gap and poses a major public health concern. ${ }^{17}$ Our finding of a lifetime OCD prevalence of $3.6 \%$ was not significantly different from that of $2.3 \%$ and $3.5 \%$ found in young adults in the Zurich and Dunedin cohort studies, respectively. ${ }^{27,28}$ In the China Mental Health Survey, lifetime and 12-month prevalence of OCD was
$2.4 \%$ and $1.6 \%$, respectively, and OCD was the second most common anxiety disorder after specific phobia. ${ }^{29} \mathrm{The}$ mean and median age of OCD onset in the population was 19.4 years and 15 years, respectively. Several studies have reported OCD onset between 15-18 years of age. ${ }^{27,30,31} \mathrm{In}$ this study, lifetime prevalence of $\mathrm{O} / \mathrm{C}$ was $11.5 \%$ and it was very similar to the $10.1 \%$ reported in the previous study ${ }^{16}$ In contrast, the Netherlands Mental Health Survey and Incidence Study and the National Comorbidity Survey in the United States (US) reported a prevalence of 5.8\% and $28.2 \%$, respectively. ${ }^{4,32}$

Our study found that the most common $\mathrm{O} / \mathrm{C}$ symptoms were ordering $(4.7 \%)$ and hoarding (4.5\%). A slight 
Table 4. Perceived Social Support and Quality of Life in Controls and Respondents with Lifetime OCD, Other Psychiatric Disorders and Physical Conditions

\begin{tabular}{|c|c|c|c|c|c|c|c|c|c|c|c|}
\hline \multirow[t]{3}{*}{ Domain } & \multirow{2}{*}{\multicolumn{2}{|c|}{$\frac{A}{\underset{O C D}{(n=217)}}$}} & \multirow{2}{*}{\multicolumn{2}{|c|}{$\begin{array}{c}\text { B } \\
\text { Psychiatric } \\
\text { Disorders } \\
(\mathbf{n}=\mathbf{2 7 1})^{\dagger}\end{array}$}} & \multirow{2}{*}{\multicolumn{2}{|c|}{$\begin{array}{c}\text { C } \\
\begin{array}{c}\text { Chronic Physical } \\
\text { Conditions } \\
(\mathbf{n}=\mathbf{3 4 1 0})^{\ddagger}\end{array}\end{array}$}} & \multirow{2}{*}{\multicolumn{2}{|c|}{$\begin{array}{c}\text { D } \\
\text { Controls }^{\S} \\
(n=2228)\end{array}$}} & \multicolumn{3}{|c|}{$P$ Value $^{*}$} \\
\hline & & & & & & & & & \multirow[t]{2}{*}{ A vs B } & \multirow[t]{2}{*}{ A vs C } & \multirow[t]{2}{*}{ A vs D } \\
\hline & Mean & SE & Mean & SE & Mean & SE & Mean & SE & & & \\
\hline \multicolumn{12}{|l|}{ Social support } \\
\hline Significant others & 22.6 & 0.4 & 22.6 & 0.46 & 23.1 & 0.1 & 23.3 & 0.1 & 0.915 & 0.019 & 0.035 \\
\hline Friends & 20.0 & 0.5 & 20.4 & 0.48 & 20.1 & 0.1 & 21.3 & 0.1 & 0.475 & $<0.001$ & $<0.001$ \\
\hline Family & 20.7 & 0.5 & 21.2 & 0.48 & 23.1 & 0.1 & 23.4 & 0.1 & 0.508 & $<0.001$ & $<0.001$ \\
\hline \multicolumn{12}{|l|}{ Quality of life } \\
\hline Physical functioning & 54.8 & 0.5 & 56.4 & 0.18 & 53.2 & 0.2 & 56.2 & 0.1 & 0.004 & 0.578 & 0.001 \\
\hline Bodily pain & 52.5 & 0.8 & 54.9 & 0.59 & 53.9 & 0.2 & 55.9 & 0.1 & 0.017 & 0.013 & $<0.001$ \\
\hline General health & 47.6 & 1.0 & 51.1 & 0.85 & 49.2 & 0.2 & 52.9 & 0.2 & 0.005 & $<0.001$ & $<0.001$ \\
\hline Vitality & 52.2 & 1.0 & 55.5 & 0.74 & 56.1 & 0.2 & 57.6 & 0.2 & 0.011 & $<0.001$ & $<0.001$ \\
\hline Social functioning & 51.4 & 0.8 & 54.1 & 0.53 & 54.6 & 0.1 & 55.9 & 0.1 & 0.007 & $<0.001$ & $<0.001$ \\
\hline Role emotional & 50.1 & 0.9 & 53.3 & 0.49 & 54.2 & 0.1 & 55.4 & 0.1 & 0.002 & $<0.001$ & $<0.001$ \\
\hline Mental health & 48.8 & 1.0 & 53.6 & 0.69 & 56.2 & 0.2 & 56.8 & 0.2 & $<0.001$ & $<0.001$ & $<0.001$ \\
\hline Mental health composite & 48.7 & 1.0 & 53.0 & 0.60 & 55.9 & 0.2 & 56.2 & 0.2 & $<0.001$ & $<0.001$ & $<0.001$ \\
\hline Physical health composite & 53.6 & 0.6 & 54.9 & 0.38 & 51.9 & 0.2 & 55.1 & 0.1 & 0.067 & 0.991 & 0.001 \\
\hline
\end{tabular}

OCD: Obsessive-compulsive disorder; SE: Standard error

"Controlled for age, gender and ethnicity.

'Exclude those with OCD.

Exclude those with comorbid OCD.

\$Without any physical conditions and psychiatric disorders.

decrease in hoarding from 4.6\% in SMHS 2010 was observed, but an increase in ordering symptoms from $2.8 \%$ in SMHS 2010 was seen. ${ }^{16}$ In the US, Ruscio et al ${ }^{4}$ reported that checking (15.4\%) and hoarding (14.4\%) were the most common symptoms. In the Dunedin cohort, harm/ checking was the most frequently reported symptom. ${ }^{28} \mathrm{~A}$ meta-analysis of 21 studies that involved $>5000$ subjects described 4 major symptom dimensions in OCD: cleaning, forbidden thoughts, hoarding and symmetry. ${ }^{33}$ Studies have also observed unique patterns in comorbidity, ${ }^{34}$ illness trajectory, heritability ${ }^{35}$ and treatment response of OCD symptom dimensions. ${ }^{36}$

Nicolini et a ${ }^{37}$ suggested that culture may play a vital role in the typology of $\mathrm{O} / \mathrm{C}$ symptoms. For example, they theorised that in Middle Eastern populations a strong focus on religion and its significance may lead to obsessions with religious themes. ${ }^{38}$ In India, the compulsions of cleanliness and pollution are more prevalent since purifying and cleansing rituals feature prominently in Hinduism. ${ }^{39}$ In the African-American population, it was hypothesised that the compulsions linked to cleanliness are rooted in the political history of racial segregation in the US..$^{40}$ Further research is needed on the role culture plays in $\mathrm{O} / \mathrm{C}$ symptoms in Singapore.

In respondents with lifetime and 12-month OCD, prevalence was lower in older individuals and higher in the young population. This finding was consistent with other epidemiological studies. ${ }^{4,41}$ While we did not find a significant gender difference in OCD prevalence among respondents with lifetime OCD, it was more likely to be associated with female gender among those with 12-month disorder. While a number of genetic and environmental factors are theorised to be associated with OCD, studies have identified an association with key reproductive events in women including menarche, pregnancy, postpartum and menopause. ${ }^{42,43}$ This may explain, to an extent, the higher association with female gender. However, the current study did not collect information pertaining to the onset of OCD and reproductive events and this explanation is speculative.

Compared to Chinese ethnicity, those of Malay ethnicity had significantly higher odds of lifetime OCD. Williams and Turkeheimer ${ }^{44}$ proposed that variations 
in attitudes towards obsessions could be attributed to "racial" differences. Studies have also mooted the possibility that the relationship between obsessions and religious beliefs can be mediated by importance/control of thoughts, responsibility/threat beliefs or maladaptive cognitions (such as thought-action fusion) ${ }^{45,46}$ However, more research is needed for a greater understanding of the role religion may play in the aetiology of OCD.

In our study, OCD was highly comorbid with other psychiatric disorders including alcohol use disorder, bipolar disorder, dysthymia, GAD and MDD. Several reviews have established comorbidity of OCD with other DSM-IV disorders ${ }^{47}$ and highlighted earlier age of onset, greater symptom severity and treatment resistance in patients with comorbid illnesses.

Recent studies have identified an association between OCD and suicidality. A systematic review and metaanalysis of OCD and suicidality had reported lifetime suicidal ideation rates that ranged from $31.7 \%-63.5 \%$ in individuals with $\mathrm{OCD}$, while meta-analysis of data from 25 studies observed a moderate and significant association between suicidality and OCD. ${ }^{8}$ These findings are in line with our study. Fernández de la Cruz et $\mathrm{al}^{9}$ observed that the risks of attempted suicide and completed suicide among those with OCD were approximately 5 and 10 times higher than the general population in Sweden. Additionally, 43\% of those with OCD who died by suicide did not have any comorbid psychiatric disorders, indicating that OCD is independently associated with suicide risk.

OCD was associated with chronic pain and diabetes in the current study. Witthauer et $\mathrm{a}^{48}$ have identified an association between OCD and migraine that was included as a chronic pain condition in our study. They hypothesised that defects in serotonin metabolism are involved in the pathophysiology of both conditions. Additionally, studies have identified a link between OCD and diabetes. ${ }^{49,50} \mathrm{~A}$ role of striatal neuronal activity in whole-body glucose homeostasi ${ }^{51}$ has been suggested as a possible mechanism linking OCD to diabetes. Consequently, our findings emphasised that there is a need to monitor the metabolic health of OCD patients and for further research in this area.

Surprisingly, OCD respondents did not experience significantly lower perceived social support from family, friends and significant others than those with other psychiatric disorders. However, perceived social support in all the domains was lower than controls and respondents with physical conditions. In a Chinese study, Wang and $Z_{\text {Zhao }}{ }^{52}$ similarly reported that overall perceived social support in the 3 domains was greater in control subjects than OCD patients. Family-focused interventions - such as psychoeducation that improves understanding and results in better social support-should be incorporated into treatment programmes for OCD patients. ${ }^{53}$

Our study also concurred with the findings of systematic reviews which found that those with OCD had lower mean quality of life across multiple domains than control subjects and patients with other psychiatric disorders. This is attributed to symptom severity and comorbidity with depression and other forms of anxiety disorders. .,54-6 $^{-5}$ However, evidence also suggests that treatment with both medications and psychotherapy can improve quality of life in OCD patients. ${ }^{6,54}$

Our study has some limitations. First, it had a response rate of about $70 \%$. Due to ethical considerations, we were not able to gather information from individuals who declined to participate in the survey. Consequently, the reported prevalence may differ from that in non-responders and could lead to an under- or over-estimation of true prevalence in the general population. Second, since the study was designed as a household survey, those who resided in institutions - a population that tends to have a higher prevalence of psychiatric disorders-were excluded. We were unable to determine whether any biological or sociological factors caused the significant increase in OCD prevalence observed in this population since the last survey. Third, the OCD instrument in WMH-CIDI 3.0 was not validated in the local population; however, Ruscio et $\mathrm{al}^{4}$ found that OCD diagnoses made by CIDI had excellent individual-level concordance with clinician-administered Structured Clinical Interview for DSM diagnoses. ${ }^{4}$ Finally, data on physical conditions was based on self-report and may be under-reported due to recall bias, lack of help-seeking and clinical diagnosis.

\section{Conclusion}

Our study found a high prevalence of OCD in the multiethnic population of Singapore. It was also associated with a significant loss of quality of life. The findings of this study contribute to the literature on the association between OCD and physical conditions. In particular, the association between OCD and diabetes warrants further research. The aetiology, illness trajectory and efficacy of treatment in OCD need to be addressed in future local research.

\section{Acknowledgement}

This study was funded by the Ministry of Health, Singapore and Temasek Foundation Innovates. The funding sources had no role in the study design, collection, analysis and interpretation of data. 


\section{REFERENCES}

1. Eisen JL, Rasmussen SA. Phenomenology of obsessive-compulsive disorder. In: Stein DJ, Hollander E, editors. Textbook of Anxiety Disorders. Washington DC: American Psychiatric Publishing; 2002. p. $173-89$.

2. Crino R, Slade T, Andrews G. The changing prevalence and severity of obsessive-compulsive disorder criteria from DSM-III to DSM-IV. Am J Psychiatry 2005;162:876-82.

3. Subramaniam M, Abdin E, Vaingankar JA, Chong SA. Obsessivecompulsive disorder: prevalence, correlates, help-seeking and quality of life in a multiracial Asian population. Soc Psychiatry Psychiatr Epidemiol 2012;47:2035-43.

4. Ruscio AM, Stein DJ, Chiu WT, Kessler RC. The epidemiology of obsessive-compulsive disorder in the National Comorbidity Survey Replication. Mol Psychiatry 2010;15:53-63.

5. Dell'Osso B, Benatti B, Hollander E, Fineberg N, Stein DJ, Lochner $\mathrm{C}$, et al. Childhood, adolescent and adult age at onset and related clinical correlates in obsessive-compulsive disorder: a report from the International College of Obsessive-Compulsive Spectrum Disorders (ICOCS). Int J Psychiatry Clin Pract 2016;20:210-7.

6. Subramaniam M, Soh P, Vaingankar JA, Picco L, Chong SA. Quality of life in obsessive-compulsive disorder: impact of the disorder and of treatment. CNS Drugs 2013;27:367-83.

7. Lochner C, Fineberg NA, Zohar J, van Ameringen M, Juven-Wetzler A, Altamura AC, et al. Comorbidity in obsessive-compulsive disorder (OCD): a report from the International College of Obsessive-Compulsive Spectrum Disorders (ICOCS). Compr Psychiatry 2014;55:1513-9.

8. Angelakis I, Gooding P, Tarrier N, Panagioti M. Suicidality in obsessive compulsive disorder (OCD): a systematic review and meta-analysis. Clin Psychol Rev 2015;39:1-15.

9. Fernández de la Cruz L, Rydell M, Runeson B, D’Onofrio BM, Brander G, Rück C, et al. Suicide in obsessive-compulsive disorder: a population-based study of 36,788 Swedish patients. Mol Psychiatry 2017;22:1626-32.

10. Chong SA, Abdin E, Picco L, Pang S, Jeyagurunathan A, Vaingankar JA, et al. Recognition of mental disorders among a multiracial population in Southeast Asia. BMC Psychiatry 2016;16:121.

11. Dell'Osso B, Camuri G, Benatti B, Buoli M, Altamura AC. Differences in latency to first pharmacological treatment (duration of untreated illness) in anxiety disorders: a study on patients with panic disorder, generalized anxiety disorder and obsessive-compulsive disorder. Early Interv Psychiatry 2013;7:374-80.

12. García-Soriano G, Rufer M, Delsignore A, Weidt S. Factors associated with non-treatment or delayed treatment seeking in OCD sufferers: a review of the literature. Psychiatry Res 2014;220:1-10.

13. Bhattacharya A, Singh AR. Experiences of individuals suffering from obsessive compulsive disorder: a qualitative study. Qual Rep 2015;20:959-81.

14. Boeding SE, Paprocki CM, Baucom DH, Abramowitz JS, Wheaton MG, Fabricant LE, et al. Let me check that for you: symptom accommodation in romantic partners of adults with obsessive-compulsive disorder. Behav Res Ther 2013;51:316-22.

15. Department of Statistics, Singapore. Population Trends 2018. Available at: https://www.singstat.gov.sg/-/media/files/publications/population/ population2018.pdf. Accessed on 1 December 2019

16. Chong SA, Abdin E, Vaingankar JA, Heng D, Sherbourne C, Yap M, et al. A population-based survey of mental disorders in Singapore. Ann Acad Med Singapore 2012;41:49-66.

17. Subramaniam M, Abdin E, Vaingankar JA, Shafie S, Chua BY, Sambasivam R, et al. Tracking the mental health of a nation: prevalence and correlates of mental disorders in the second Singapore mental health study. Epidemiol Psychiatr Sci 2019;29:e29.
18. American Psychiatric Association. Diagnostic and Statistical Manual of Mental Disorders. $4^{\text {th }}$ ed. Washington, DC: APA; 1994.

19. Kessler RC, Ustün TB. The World Mental Health (WMH) Survey Initiative version of the World Health Organization (WHO) Composite International Diagnostic Interview (CIDI). Int J Methods Psychiatr Res 2004;13:93-121.

20. Goodman WK, Price LH, Rasmussen SA, Mazure C, Fleischmann RL, Hill CL, et al. The Yale-Brown Obsessive Compulsive Scale. I. Development, use, and reliability. Arch Gen Psychiatry 1989;46:1006-11.

21. Storch EA, De Nadai AS, Conceição do Rosário M, Shavitt RG, Torres AR, Ferrão YA, et al. Defining clinical severity in adults with obsessivecompulsive disorder. Compr Psychiatry 2015;63:30-5.

22. Australian Bureau of Statistics. National Survey of Mental Health and Wellbeing: Users' Guide, 2007. Available at: https://www.abs.gov.au/ ausstats/abs@.nsf/mf/4327.0. Accessed on 1 December 2019.

23. Ware J Jr, Kosinski M, Keller SD. A 12-item short-form health survey: construction of scales and preliminary tests of reliability and validity. Med Care 1996;34:220-33.

24. Zimet GD, Dahlem NW, Zimet SG, Farley GK. The Multidimensional Scale of Perceived Social Support. J Pers Assess 1988;52:30-41.

25. Vaingankar JA, Abdin E, Chong SA. Exploratory and confirmatory factor analyses of the Multidimensional Scale of Perceived Social Support in patients with schizophrenia. Compr Psychiatry 2012;53:286-91.

26. Teh WL, Shahwan S, Abdin E, Zhang Y, Sambasivam R, Devi F, et al. Confirmatory factor analysis and measurement invariance of the Multidimensional Scale of Perceived Social Support in young psychiatric and non-psychiatric Asians. Ann Acad Med Singapore 2019;48:314-20.

27. Fineberg NA, Hengartner MP, Bergbaum CE, Gale TM, Gamma A, Ajdacic-Gross V, et al. A prospective population-based cohort study of the prevalence, incidence and impact of obsessive-compulsive symptomatology. Int J Psychiatry Clin Pract 2013;17:170-8.

28. Fullana MA, Mataix-Cols D, Caspi A, Harrington H, Grisham JR, Moffitt TE, et al. Obsessions and compulsions in the community: prevalence, interference, help-seeking, developmental stability, and co-occurring psychiatric conditions. Am J Psychiatry 2009;166:329-36.

29. Huang Y, Wang Y, Wang H, Liu Z, Yu X, Yan J, et al. Prevalence of mental disorders in China: a cross-sectional epidemiological study. Lancet Psychiatry 2019;6:211-24.

30. De Luca V, Gershenzon V, Burroughs E, Javaid N, Richter MA. Age at onset in Canadian OCD patients: mixture analysis and systematic comparison with other studies. J Affect Disord 2011;133:300-4.

31. Angst J, Gamma A, Endrass J, Goodwin R, Ajdacic V, Eich D, et al. Obsessive-compulsive severity spectrum in the community: prevalence, comorbidity, and course. Eur Arch Psychiatry Clin Neurosci 2004;254:156-64

32. De Bruijn C, Beun S, De Graaf R, Ten Have M, Denys D. Subthreshold symptoms and obsessive-compulsive disorder: evaluating the diagnostic threshold. Psychol Med 2010;40:989-97.

33. Bloch MH, Landeros-Weisenberger A, Rosario MC, Pittenger C, Leckman JF. Meta-analysis of the symptom structure of obsessivecompulsive disorder. Am J Psychiatry 2008;165:1532-42.

34. Prabhu L, Cherian AV, Viswanath B, Kandavel T, Math SB, Janardhan Reddy YC. Symptom dimensions in OCD and their association with clinical characteristics and comorbid disorders. J ObsessiveCompuls Relat Disord 2013;2:14-21.

35. Katerberg H, Delucchi KL, Stewart SE, Lochner C, Denys DA, Stack DE, et al. Symptom dimensions in OCD: item-level factor analysis and heritability estimates. Behav Genet 2010;40:505-17.

36. Mataix-Cols D, Marks IM, Greist JH, Kobak KA, Baer L. Obsessivecompulsive symptom dimensions as predictors of compliance with and response to behaviour therapy: results from a controlled trial. Psychother Psychosom 2002;71:255-62. 
37. Nicolini H, Salin-Pascual R, Cabrera B, Lanzagorta N. Influence of culture in obsessive-compulsive disorder and its treatment. Curr Psychiatry Rev 2017;13:285-92.

38. Mahintorabi S, Jones MK, Harris LM, Zahiroddin A. Religious observance and obsessive compulsive washing among Iranian women. J Obsessive-Compuls Relat Disord 2015;7:35-42.

39. Khanna S, Channabasavanna SM. Phenomenology of obsessions in obsessive-compulsive neurosis. Psychopathology 1988;21:12-8.

40. Williams MT, Steever A. Cultural manifestations of obsessivecompulsive disorder. In: Lack CW, editor. Obsessive-Compulsive Disorder: Etiology, Phenomenology, and Treatment. Fareham, UK: Onus Books; 2015. p. 63-84.

41. Osland S, Arnold PD, Pringsheim T. The prevalence of diagnosed obsessive compulsive disorder and associated comorbidities: a population-based Canadian study. Psychiatry Res 2018;268:137-42.

42. Guglielmi V, Vulink NC, Denys D, Wang Y, Samuels JF, Nestadt G. Obsessive-compulsive disorder and female reproductive cycle events: results from the OCD and reproduction collaborative study. Depress Anxiety 2014;31:979-87.

43. Alpak G, Karamustafalioglu O. Female reproductive cycle events in symptom worsening and onset of obsessive-compulsive disorder. Eur Neuropsychopharmacol 2009;19:S592.

44. Williams MT, Turkheimer E. Identification and explanation of racial differences on contamination measures. Behav Res Ther 2007;45:3041-50.

45. Inozu M, Karanci AN, Clark DA. Why are religious individuals more obsessional? The role of mental control beliefs and guilt in Muslims and Christians. J Behav Ther Exp Psychiatry 2012;43:959-66.

46. Williams AD, Lau G, Grisham JR. Thought-action fusion as a mediator of religiosity and obsessive-compulsive symptoms. J Behav Ther Exp Psychiatry 2013;44:207-12.

47. Pallanti S, Grassi G, Sarrecchia ED, Cantisani A, Pellegrini M. Obsessivecompulsive disorder comorbidity: clinical assessment and therapeutic implications. Front Psychiatry 2011;2:70.
48. Witthauer C, Gloster AT, Meyer AH, Lieb R. Physical diseases among persons with obsessive compulsive symptoms and disorder: a general population study. Soc Psychiatry Psychiatr Epidemiol 2014;49:2013-22.

49. Isomura K, Brander G, Chang Z, Kuja-Halkola R, Rück C, Hellner $\mathrm{C}$, et al. Metabolic and cardiovascular complications in obsessivecompulsive disorder: a total population, sibling comparison study with long-term follow-up. Biol Psychiatry 2018;84:324-31.

50. Kontoangelos K, Raptis AE, Papageorgiou CC, Papadimitriou GN, Rabavilas AD, Dimitriadis G, et al. The association of the metabolic profile in diabetes mellitus type 2 patients with obsessive-compulsive symptomatology and depressive symptomatology: new insights. Int $\mathbf{J}$ Psychiatry Clin Pract 2013;17:48-55.

51. TerHost KW, Lammers NM, Trinko R, Opland DM, Figee M, Ackermans MT, et al. Striatal dopamine regulates systemic glucose metabolism in humans and mice. Sci Transl Med 2018;10:eaar3752.

52. Wang J, Zhao X. Comparison of family functioning and social support between families with a member who has obsessive-compulsive disorder and control families in Shanghai. Shanghai Arch Psychiatry 2012;24:20-9.

53. Maina G, Saracco P, Albert U. Family-focused treatments for obsessivecompulsive disorder. Clin Neuropsychiatry 2006;3:382-90.

54. Macy AS, Theo JN, Kaufmann SC, Ghazzaoui RB, Pawlowski PA, Fakhry HI, et al. Quality of life in obsessive compulsive disorder. CNS Spectr 2013;18:21-33.

55. Picco L, Lau YW, Pang S, Jeyagurunathan A, Vaingankar JA, Abdin $\mathrm{E}$, et al. Predictors of general functioning and correlates of quality of life: a cross-sectional study among psychiatric outpatients. Ann Acad Med Singapore 2018;47:3-12.

56. Subramaniam M, Abdin E, Vaingankar JA, Picco L, Chong SA. Hoarding in an Asian population: prevalence, correlates, disability and quality of life. Ann Acad Med Singapore 2014;43:535-43. 